\title{
PLANIFICACIÓN URBANA E INFRAESTRUCTURA EN TIEMPOS VIOLENTOS: LA CIUDAD DE SANTA FE (ARGENTINA) DURANTE LA ÚLTIMA DICTADURA MILITAR
}

\author{
Urban planning and infrastructure in violent times: Santa Fe city (Argentinian) \\ during the last military dictatorship
}

\author{
Gisela Ariana Rausch* \\ http://orcid.org/0000-0002-5851-3357
}

\section{Resumen}

Tanto los planes de ordenamiento territorial como las grandes infraestructuras fueron considerados dentro de la ideología desarrollista como soluciones técnicas a problemas definidos objetivamente. Esta pretendida neutralidad que se les ha asignado deriva de la pretendida neutralidad tecno-científica moderna y ha invisibilizado la condición intensamente política de los mismos. Asimismo, ha posibilitado que se promuevan indistintamente por diferentes sectores políticos sin modificaciones sustanciales en los proyectos. El artículo propone un análisis en perspectiva histórica de dos proyectos estatales que abarcaron varias décadas del siglo XX, pero cuyo mayor auge tuvo lugar durante la última dictadura militar (19761983). En general, pretendemos destacar la condición política e histórica de los objetos técnicos, y en particular, colocar en relieve las estrategias específicas de apropiación política y simbólica que el gobierno dictatorial realizó sobre los dos proyectos en cuestión.

$$
<\text { Planificación }><\text { Infraestructura }><\text { Dictadura }><\text { Grandes proyectos estatales }>
$$

\begin{abstract}
Large infrastructures and territorial plans were considered by the ideology of Developmentalism as technical solutions to problems objectively defined. This so-called neutrality stems from the modern assumption about techno-scientific neutrality, and it has overshadowed the intensely political status of the aforementioned infrastructures and territorial plans. It also allowed their promotion by different political sectors without significant changes in the projects. The article proposes an historical analysis of two State projects which extended over several decades of the 20th century, with major boost during the last military dictatorship (1976-1983). In general, we aim to highlight the political and historical status of technical objects. In particular, we intend to outline the specific strategies of political and symbolic appropriation displayed by the military dictatorship over the two projects.
\end{abstract}

$<$ Planning $><$ Infrastructure $><$ Dictatorship $><$ State projects $>$

Recibido: 24/04/2019

Aceptado: 23/07/2019

\footnotetext{
* Consejo Nacional de Investigaciones Científicas y Técnicas (CONICET), sede Centro Universitario Rosario de Investigaciones Urbanas y Regionales (CURDIUR), Facultad de Arquitectura Planeamiento y Diseño, Universidad Nacional de Rosario, Argentina. gsrrsch@gmail.com
} 
Rausch. Planificación urbana e infraestructura en tiempos violentos: la ciudad de Santa Fe (Argentina) durante...

\section{Introducción}

Muchos de los planes y proyectos territoriales en Argentina tienen una característica común: atraviesan largos procesos -contados en décadas- con interrupciones y atrasos desde su formulación hasta su concreción, siendo apropiados políticamente por distintos gobiernos, sufriendo variaciones y revisiones, a veces concretándose en parte o permaneciendo durante décadas como el original. A partir de esta observación, la indagación tuvo como intención inicial reposar la mirada sobre dos proyectos territoriales estatales que abarcaron varios años en sus procesos de formulación, siendo impulsados con mayor fuerza durante la última dictadura militar (UDM $\left.{ }^{1}\right)$ : el Plan Director para la ciudad de Santa Fe (PD) y el Proyecto Hidroeléctrico Paraná Medio (PHPM).

El trabajo se fue gestando a partir de dos motivaciones principales: la primera, fue haber advertido -a partir de investigaciones previas en la temática- ciertas continuidades en los proyectos territoriales propuestos por la UDM respecto de gobiernos precedentes (incluso del peronismo con quién antagonizaba ferozmente). Dichas continuidades podrían pasar inadvertidas en estudios enfocados en los aspectos meramente políticos o económicos, por cuanto esta dictadura se propuso marcar una ruptura con los gobiernos anteriores (Ferrer, 2004), asumiendo como ambición principal la apertura de un nuevo ciclo histórico (Canelo, 2016). Sin embargo, pudo observarse que los proyectos propuestos, y en particular los que aquí analizamos, formaron parte de un largo proceso de formulación, atravesando varias décadas durante la segunda mitad del siglo XX, sin modificaciones sustanciales en sus planteamientos.

La segunda motivación partió de una reflexión acerca de dichas continuidades advertidas y que, a nuestro entender, podrían comprenderse en dos niveles: de modo general, a partir del rol que pretendidamente se les ha asignado a los objetos técnicos en los procesos de modernización durante el siglo XX, como piezas políticamente neutrales. Y de modo particular, a partir de la consideración por parte de la ideología desarrollista, tanto de los planes territoriales como de las infraestructuras, como soluciones técnicas destinadas a subsanar determinados problemas definidos objetivamente. Esta neutralidad política que se les ha atribuido a dichos objetos, junto a un estatuto de verdad objetiva que los legitima, ha invisibilizado la condición intensamente política de los mismos, posibilitando que se promuevan indistintamente por sectores políticos de posiciones muy diversas. En este sentido, el análisis que se presenta intenta, de modo general, restablecer la mirada sobre la condición histórico-política de los objetos técnicos y en particular, colocar en relieve las apropiaciones específicas y estratégicas que la UDM realizó sobre los dos proyectos en cuestión. Cabe aclarar que si bien ambas propuestas constituyen proyectos de diferentes escalas y órdenes (uno, es un plan de ordenamiento urbano-regional y el otro, un proyecto hidroeléctrico) ${ }^{2}$, ambos proyectos se encontraban vinculados: el gobierno de la UDM proyectó el emprendimiento hidroeléctrico como

\footnotetext{
1 Con esta sigla se referirá al gobierno autodenominado Proceso de Reorganización para diferenciarlo de los gobiernos dictatoriales argentinos precedentes. Aquí se consideran las particularidades de este último gobierno de facto, y al mismo tiempo, se pretende evitar la denominación que ellos mismos se asignaron.

2 De ahí que nuestro trabajo no consiste en un ejercicio de comparación.
} 
parte de la propuesta de ordenamiento territorial del PD en el marco del sistema de infraestructura de escala regional que planteaba.

Para el análisis de ambos proyectos han sido un aporte relevante las indagaciones de Canelo (2016) sobre la UDM y la consideración de este gobierno como un complejo de tres fuerzas heterogéneas en franco conflicto, con visiones y posiciones políticas y económicas diversas -incluso contrapuestas-, cuya estabilidad y cohesión se mantenía a través del consenso subversivo. Según desarrolla la autora, dicho consenso aunaba las tres fuerzas en la lucha antisubversiva ${ }^{3}$ (Canelo, 2016, pp. 43-48).

Dentro de dicha heterogeneidad, la historiadora identifica las siguientes fracciones: 1) los duros, fuerza representada por la elite conocida como los señores de la guerra (Canelo, 2008, p.74) ${ }^{4}$, eran corporativistas, antiperonistas y anticomunistas y la ideología nacionalista-desarrollista que defendían se basaba en una crítica al individualismo liberal, en la apología de la autoridad, el orden y la unidad del cuerpo nacional sumado a un "renovado entusiasmo por el industrialismo y la modernización económica"(Canelo, 2016, p. 52); 2) los politicistas, quienes poseían una mirada pragmática sobre los objetivos de la dictadura ${ }^{5}$, dialogando con sindicatos y partidos políticos. Al igual que los duros, esta fracción se oponía a la política económica liberal; y 3) por último, la autora identifica a la fracción moderada ${ }^{6}$, de ideología liberal y considera que su rol principal fue "moderar la interna intrafuerzas del Ejército" (Canelo, 2016:52) entre las fuerzas antes mencionadas.

El primer caso de análisis, el PD para Santa Fe, comenzó a confeccionarse desde finales de la década de 1960 y fue puesto en vigencia en 1980. Ha sido analizado en los últimos años desde la Historia reciente en Alonso y Citroni (2008), Citroni (2011) y objeto de nuestro análisis en Rausch $(2010 ; 2013)$. A partir de estos antecedentes, se pretende, por un lado, avanzar en el análisis abordando históricamente las ideas que sustentaron dicho plan en vinculación con el campo más amplio de la planificación en Argentina.Y por el otro, dar cuenta acerca de los modos específicos en que dicho plan fue implementado en relación a los objetivos políticos de la UDM en la escala municipal.

El segundo caso, el PHPM (nunca concretado) estuvo vigente durante cuatro décadas: desde 1958 hasta 1997. Su mayor impulso lo tuvo durante el gobierno de Jorge Videla (1976-1981), y luego fue retomado en 1995 por el gobierno de Carlos Menem ${ }^{7}$ (1989-1999). Puede considerarse una pieza relevante para el posicionamiento del ala dura de las fuerzas militares, funcional a las ideas desarrollistas-nacionalistas y a las políticas estatistas que promovió esta fracción.

3 Canelo define el consenso antisubversivo como un acuerdo en el seno del gobierno orientado a la eliminación de la subversión, para cuyo objetivo se desplegó el aparato militar a través de diferentes acciones de terrorismo de Estado.

4 La autora menciona aquí a Ramón D. Bessone, Carlos G. Suárez Mason, Luciano B. Menéndez, entre otros.

5 Aquí la autora menciona a Roberto Viola, Horacio T. Liendo, José R. Villareal, entre otros.

6 Como exponentes principales de esta fracción, la autora menciona a Jorge F. Videla, a Leopoldo Galtieri y José A. Martínez de Hoz.

7 Presidente del partido Justicialista, llevó adelante la Reforma del Estado y la implementación de políticas neoliberales durante sus dos mandatos en la década de 1990. 
Rausch. Planificación urbana e infraestructura en tiempos violentos: la ciudad de Santa Fe (Argentina) durante...

La indagación se realizó desde el campo de los Estudios Territoriales y la Historia Urbana. Se utilizaron fuentes documentales sobre ambos proyectos producida por organismos y administraciones públicas, que se complementaron con publicaciones especializadas oficiales y dos entrevistas abiertas realizadas a técnicos involucrados. En el primer apartado, se realiza un breve repaso por las condiciones histórico-disciplinares del planeamiento regional en Argentina en que tuvieron lugar ambos proyectos territoriales. En el segundo apartado, se analiza el PD como producto de un largo y heterogéneo proceso que culminó en la particular apropiación que efectuó la última dictadura militar, en sus objetivos de alcanzar el consenso social para legitimar la lucha antisubversiva a través del rol clave que le asignó a las municipalidades. En el tercer apartado, se analiza el PHPM como pieza geopolítica relevante propuesta por el ala dura de la UDM, y cuyo objetivo hacia finales de la década de 1970 era imponer su visión desarrollista-nacionalista que por esos años ya estaba en franco declive dentro de las fuerzas militares. Finalmente se presentan las conclusiones del análisis.

\section{Modernización, desarrollo e integración urbano-regional: antecedentes y derivas de la planificación urbana desarrollista en Argentina}

Graham y Marvin (2002) han señalado que el paradigma fordista de la segunda posguerra, sustentado en la gestión científica, organización racional y producción masiva de bienes estandarizados, estuvo basado en la explotación del potencial de los nuevos sistemas infraestructurales como soporte de las sociedades industriales. De este modo, los enclaves infraestructurales urbanos pasaron a constituirse en "interconexiones reguladas de la extensión" (Graham y Marvin, 2002, p. 41). Tal es así que los planes de este período, basados en la idea de planificación racional y comprensiva tuvieron al planeamiento regional y al desarrollo de los sistemas infraestructurales como elementos claves del proceso, cuyo sentido último era desarrollar el proyecto moderno de una racionalidad universal, aplicada a todas las áreas de la vida social. La creencia en el poder de transformación positiva de la ciencia moderna y de los sistemas tecnológicos (Mattelart, 1994) junto a las teorías y prácticas del planeamiento urbano moderno, sustentaron la construcción de dicho ideal infraestructural moderno. Se pasaba así -dicho esquemáticamente-, del Urbanismo como disciplina abocada a ordenar y embellecer la ciudad, a la idea de planeamiento, donde los sistemas infraestructurales -fijaciones espaciales de los flujos capitalistas en expansión (Harvey, 1982)- operarían las interconexiones entre ciudades, así como también entre el espacio urbano y rural. Visto desde esta perspectiva, puede decirse que comenzaba a regularse la extensión al tiempo que emergían los debates sobre la región.

Antes de proseguir con el texto, consideramos necesario hacer una aclaración: tanto en las fuentes documentales como en la bibliografía específica analizada, se ha advertido el uso indiferenciado y muchas veces confuso del término planeamiento (o planificación). En general, los urbanistas y arquitectos han utilizado planeamiento para referir a la acción de regular y organizar espacialmente las diversas actividades y dinámicas de la vida social; mientras que los economistas, sociólogos y otras disciplinas 
abocadas a los estudios sobre desarrollo, lo han utilizado sin involucrar las cuestiones espaciales, o bien haciéndolo de modo muy general y teórico, a través de los modelos ${ }^{8}$. Para salvar la confusión, este artículo propone el término planeamiento para el desarrollo para referir a un conjunto heterogéneo de teorías y prácticas concebidas y llevadas adelante, desde la segunda posguerra por los Estados nacionales (y otros organismos funcionales a éste), cuyo objetivo principal fue el crecimiento económico y social de los países. Tales teorías y prácticas, que convergerían en programas y planes concretos de desarrollo, respondían a la clasificación entre países desarrollados y subdesarrollados. Así, puede considerarse que los ideales que orientaron el planeamiento para el desarrollo fueron básicamente tres: 1) la idea de modernización entendida como urbanización, industrialización y equilibrio poblacional; 2) la idea de desarrollo, entendida como proceso de evolución, ya sea hacia sociedades de consumo (Rostow, 1960); o bien como proceso desde una condición de subdesarrollo a una desarrollada ${ }^{9}$; y 3) la idea de integración coherente, que hacía referencia tanto a la integración económica de los diferentes países en el cuadro mundial capitalista (hegemonizado, en este período por Estados Unidos) como a la integración espacial conformando un sistema.

Por otra parte, se utilizará planeamiento urbano y regional, para referir a las elaboraciones de profesionales urbanistas y arquitectos trabajando en oficinas técnicas, cuya finalidad era organizar las distintas dinámicas urbanas y su extensión a través del diseño de propuestas espaciales, equipamiento y artefactos infraestructurales. Estas elaboraciones se inscribían en los planes de desarrollo generales (de escala nacional) articulándose con éstos en mayor o menor medida, según los casos específicos.

En Argentina, la idea de planeamiento puede considerarse desde 1943, acompañando la noción de un Estado promotor del desarrollo (Mazza, 2008). En particular, la idea de planeamiento regional como disciplina de ordenamiento territorial ha sido atribuida al arquitecto José Pastor (Rigotti, 2004; Mazza, 2008). A mediados de la década de 1940, este arquitecto concretó una serie de publicaciones que alentaban a considerar el pasaje del Urbanismo al planeamiento. Para Gutiérrez (2016) dicho pasaje significaba un cambio en la metodología específica de la disciplina que implicó un viraje en el modo de proyectar por parte de los urbanistas (Novick y Piccioni, 1998), mientras que Kullock (2010) ha destacado que dichos planteamientos eran coherentes con el contexto más general de aplicación del modelo desarrollista de industrialización durante la mencionada década.

Asimismo, el planeamiento regional en Argentina fue influenciado principalmente por las experiencias de Inglaterra y Estados Unidos (Rigotti, 2004) y en menor medida, por Alemania (Mazza, 2008; Gutiérrez, 2016). La labor teórica de

8 Sería el caso de Christaller (1933, ed. 1966) y Perroux (1955 y 1988).

9 Las teorías del desarrollo conforman un vasto campo de elaboraciones desde múltiples perspectivas, desde las asentadas en las teorías económicas clásicas (como la de Rostow) hasta propuestas latinoamericanas (como las de la Comisión Económica Para América Latina - CEPAL) con matices marxistas. Sin embargo, más allá de las diferencias en los análisis, todas las teorías proponían el Desarrollo como sentido histórico inequívoco de las sociedades. Para ampliar, puede verse: Escobar (2007); Rist (2008); Sachs (2010). 
Rausch. Planificación urbana e infraestructura en tiempos violentos: la ciudad de Santa Fe (Argentina) durante...

Pastor, sistematizando las visiones anglosajonas y norteamericana ${ }^{10}$ (Rigotti, 2004), se desarrolló principalmente durante la primera presidencia de Juan D. Perón (1946-1952). Según ha señalado Mazza (2008, p.56), tanto sus escritos como sus planes regionales "constituyeron un modo de análisis y prospectiva del territorio, un concepto de la región de planeamiento y principalmente un modo técnico de intervención planificada". La prédica de esta entidad hacía énfasis en la descentralización de las reparticiones de planeamiento y en la participación democrática.

Entre las problemáticas principales que, según Pastor, debía encarar el planeamiento regional se encontraban: primero, ordenar el caos causado por la suburbanización de la industria y los barrios residenciales que estaban provocando el desalojo de los cultivos periurbanos. Para esto, el arquitecto proponía ordenar el crecimiento en un sistema urbano coherente. Segundo, y en relación a la problemática anterior, postulaba proyectar la descentralización de las ciudades. De este modo, se lograba integrar lo urbano y lo rural evitando el desparramo de población (Pastor, 1947, p.5). Tercero, prescribía estructurar los planes regionales en torno a las cuencas fluviales de Argentina. Para el arquitecto, los ríos constituían el eje de los planes regionales. Cuarto, señalaba la necesidad de confeccionar expedientes regionales consistentes en inventarios de recursos sociológicos y tecnológicos. Y quinto, apuntaba a superar la actitud pasiva frente a los recursos naturales, que según consideraba, había prevalecido en Argentina hasta ese momento. Esta actitud, que Pastor denominaba pasiva, refería a una intención de incorporar determinados elementos de la naturaleza (principalmente los ríos) a los circuitos productivos.

Una cuestión que destaca Rigotti sobre el arquitecto, es su horror por las barriadas suburbanas y las ciudades de cartón. Para la autora, Pastor "rechazaba sus callejuelas, su carencia de espacios libres" (Rigotti, 2004, p. 7), considerando que debían ser reemplazados por barrios higiénicos y alegres. Para este arquitecto los suburbios eran lugares donde se derrumbaba el civismo y la moral popular, por tanto, la regeneración social mediante el planeamiento adquiría niveles de urgencia en aras de revitalizar las condiciones materiales y espirituales de este sector social.

Básicamente, el planeamiento propuesto por Pastor ${ }^{11}$, concebía a la ciudad dentro de una escala más amplia (la región) y su objetivo era ordenarla, armonizando lo urbano con lo rural. Esta armonización debía realizarse no sólo desde la dimensión física (que el arquitecto le atribuye al Urbanismo) sino también, desde la dimensión socio-territorial. Es decir, atendiendo a las necesidades sociales y a los recursos naturales, económicos e institucionales, entre otros. Dentro de este esquema conceptual, las acciones de planeamiento se instrumentarían a través de una nueva legislación urbano-regional.

${ }^{10}$ Rigotti (2004) destaca que el arquitecto se inspiró en el populismo tecnocrático promovido por la experiencia norteamericana de la Tennessee Valley Authority, creada en el marco del New Deal.

${ }^{11}$ La obra de Pastor es vasta y ha sido sujeta de interesantes lecturas. Para ampliar, ver las obras citadas de: Rigotti (2004 y 2007); Gutiérrez (2016); Mazza (2008); Novick y Piccioni (1998). 


\section{Ordenar el caos urbano y planificar el crecimiento anárquico: el Plan Director de 1980 para la ciudad de Santa Fe}

En 1966, se creaba la Dirección de Planeamiento Urbano y Proyectos Municipal (DPUyPM) de la ciudad de Santa Fe, cuando ya habían pasado dos décadas desde las propuestas urbanísticas de Pastor. Sin embargo, no es hasta 1968 que se iniciaron las tareas para confeccionar un plan urbano para la ciudad, cuya finalización y aprobación recién llegaría el 14 de agosto de $1980^{12}$. Durante esos años se sucedieron en Argentina ocho presidencias que se alternaron entre gobiernos de facto y electos democráticamente, tres directores en la oficina municipal dedicada a confeccionar el $\operatorname{Plan}^{13}$ y dos versiones de este último. Las consideraciones encontradas, y a veces contradictorias, por parte de los técnicos entrevistados, sumado a la negativa de otros a acceder a dichas entrevistas, hizo difícil el acceso a este momento de la historia urbanística de la ciudad, acrecentando su complejidad.

Puede decirse que el PD constituye, en Santa Fe, el primer plan urbano que incorpora la idea de región y despliega una mirada integradora entre el centro urbano consolidado y la periferia en la que, hasta ese momento, coexistían los usos rurales y suburbanos de varios tipos (fábricas, residencias de fin de semana, por ejemplo). Si bien el plan aprobado tuvo modificaciones respecto de las primeras propuestas ${ }^{14}$, puede observarse que el planteamiento básico (ver Fig. 1) tomaba a la Laguna Setúbal (perteneciente al sistema fluvial Paraná) como elemento central e integrador del territorio, configurando así la vinculación del centro urbano con la costa ${ }^{15}$ (área que hasta ese momento tenía características rurales y semi-urbanas).

La propuesta general consistía en una red de conexiones que posicionaban a Santa Fe como nodo regional (ver Fig. 2) a partir de un sistema de comunicación ferro-vial16 que conectaba tres elementos a diferentes escalas: 1) el emprendimiento hidroeléctrico del Paraná Medio, 2) el centro urbano santafesino y su área suburbana y 3 ) las ciudades de Reconquista, Corrientes, Córdoba, Resistencia y Paraná. De esta manera, Santa Fe se establecía como el nexo entre el área mesopotámica y la salida marítima tradicional, al Atlántico (en Buenos Aires); y al mismo tiempo, el PHPM consolidaba a través del embalse en el río Paraná, el eje Norte-Sur del país.

\footnotetext{
${ }^{12}$ MSF. Ordenanza N ${ }^{\circ} 7871,1980$. Archivo del Concejo Deliberante Municipal. Tomo 1980, fjs. 341.

${ }^{13}$ Waldemar Giacomino y Norberto Nardi, en la versión conocida como Plan Nardi; y Edgardo Gambini para el plan aprobado en 1980.

${ }^{14}$ Una lectura más detallada sobre las propuestas originales y las aprobadas puede verse en: Rausch (2010). Se sugiere unificar la forma de citado entre esta nota al pie, la número 9 y 50.

${ }^{15}$ Así se denomina localmente esta área que forma parte del valle aluvial del río Paraná.

${ }^{16}$ Este proyecto de reestructuración ferroviaria provenía del año 1969 cuando la municipalidad había contratado a la Empresa Ferrocarriles Argentinos para elaborar el Plan de Sistematización. Estas propuestas fueron publicadas tardíamente en: MSF, 1981.
} 


\section{ARTículOS}

Rausch. Planificación urbana e infraestructura en tiempos violentos: la ciudad de Santa Fe (Argentina) durante...

Figura 1: Plano síntesis de las propuestas urbanísticas

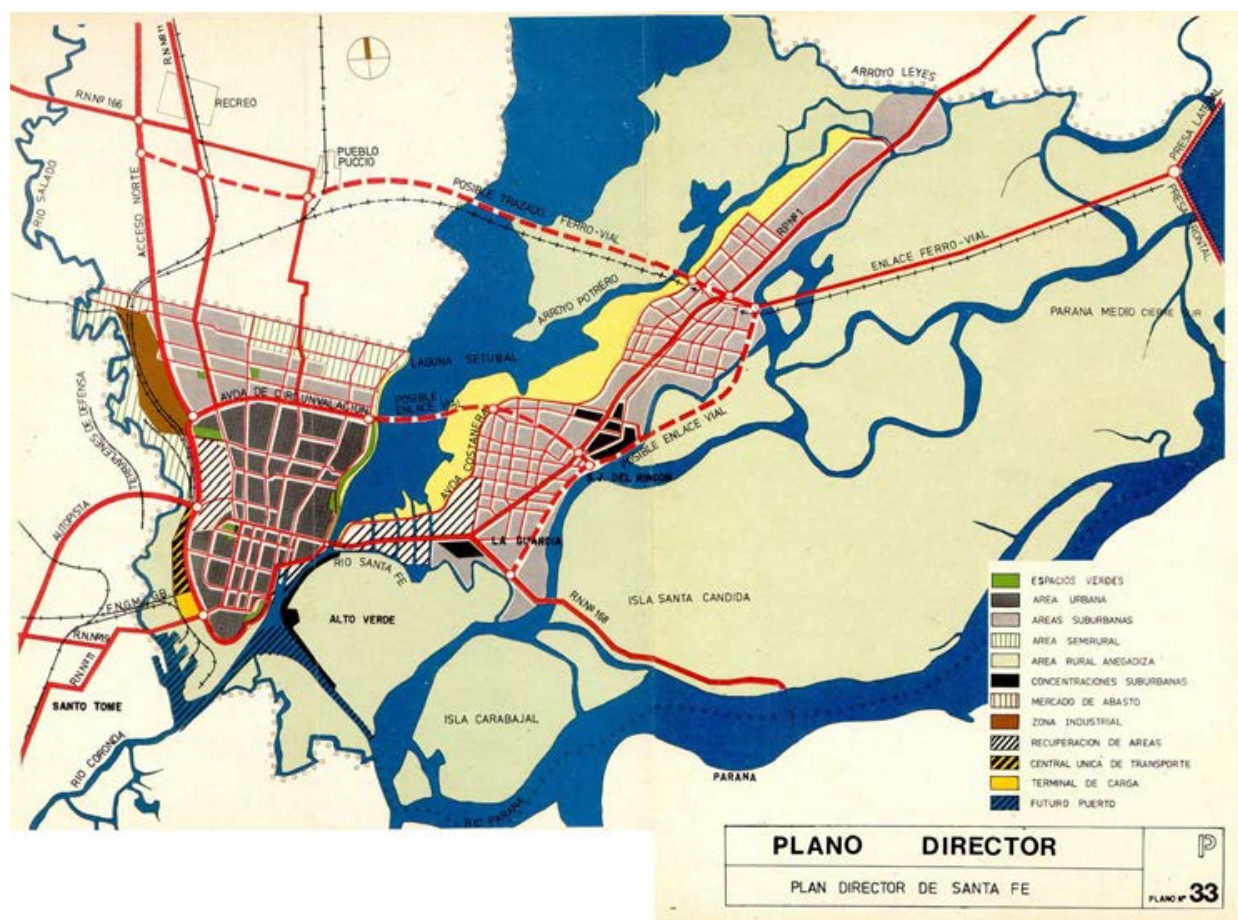

Fuente: PD, 1980. Plano No 33

Figura 2: Conexiones viales en la propuesta del PD y el PHPM

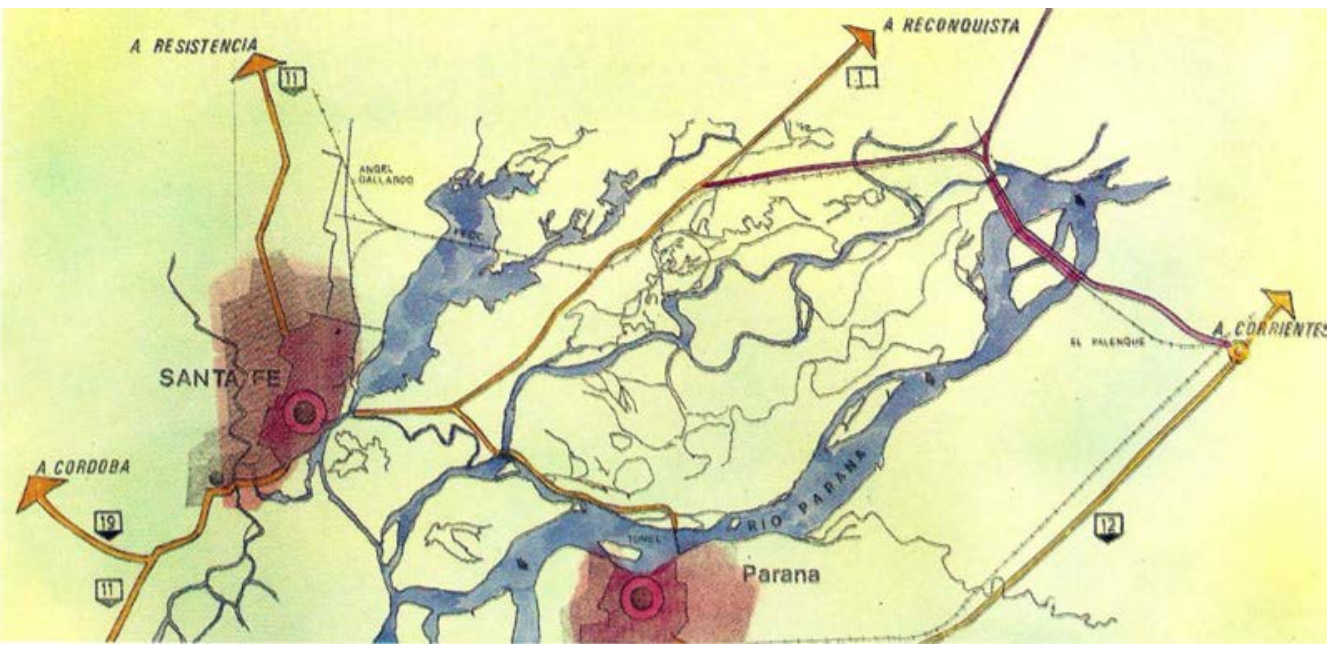

Fuente: Agua y Energía Eléctrica, s/f ${ }^{17}$.

${ }^{17}$ El documento no tiene fecha, se estima que es posterior a 1978 y consiste en un folleto de promoción del PHPM. 
A continuación se desarrolla una interpretación del Plan Director a partir de las fuentes relevadas y de estudios históricos sobre ese período.

\section{Doble origen, doble dirección: las condiciones de partida del PD en el marco del Sistema Nacional de Planeamiento}

El PD tuvo dos vertientes fundamentales de ideas, que lo nutrieron en sus inicios: por un lado, la versión francesa, la cual planteaba una combinación de centralidad administrativa con descentralización espacial, y por el otro, la vertiente norteamericana, de orientación populista y propuesta descentralizadora. Esta doble vertiente se debió a que, durante los primeros años de confección, la oficina técnica de planeamiento en Santa Fe poseía una doble dirección conformada por los arquitectos Waldemar Giacomino ${ }^{18} \mathrm{y}$ Norberto Nardi ${ }^{19}$. Estos arquitectos habían desarrollado su formación y experiencia en el planeamiento francés y norteamericano, respectivamente.

Para tener una somera idea de ambas vertientes, puede decirse que en la francesa (surgida en la era fordista) las principales referencias fueron las elaboraciones de François Perroux. Este economista propuso la idea de polos de crecimiento, cuya finalidad era reorientar y redistribuir espacialmente las actividades concentradas en determinadas zonas. Este período del planeamiento francés puede considerarse iniciado con el Plan Rector de 1965 en el cual trabajó el arquitecto Giacomino ${ }^{20}$. El plan francés incorporaba las nociones de regulación del crecimiento suburbano y de expansión urbana hacia la periferia, delineándose en una gestión administrativamente centralizada en el gobierno nacional y llevada adelante a través de diversas oficinas técnicas (Antier, 2013).

Por otro lado, la experiencia norteamericana de planeamiento, que constituyó el marco de referencia de Nardi, remite a la Tennessee Valley Authority (TVA), y particularmente a la National Resources Planning Board (1933-1943), que era la agencia nacional de planeamiento en Estados Unidos, bajo la dirección del presidente Franklin Roosevelt (1933-1945). Este organismo centralizado en la figura del presidente tenía como objetivo implementar las políticas del New Deal, de corte populista tecnocrático y fuertemente economicista, a partir de una organización descentralizada de las distintas reparticiones, orientadas a favorecer al participación ciudadana y el consenso (Rigotti, 2003). Como ha señalado Rigotti, existía en esta vertiente del planeamiento una noción de planificación democrática, proveniente de las ideas aportadas por el economista Rexford Tugwell, cerebro principal de la política del presidente estadounidense. La experiencia que Nardi había tenido en la Junta de Planificación de Puerto Rico lo acercó a esta visión del planeamiento.

\footnotetext{
${ }^{18}$ Entre 1962 y 1965, Giacomino había trabajado en un estudio de planificación urbana, en París, participando en el Plan de desarrollo para la costa francesa sobre el Mediterráneo: la costa de Roussillon.

${ }^{19}$ Se había formado en la Escuela Graduada en Planificación en Puerto Rico. En los años 60s, Puerto Rico ya era un país relevante en materia de planificación que seguía la línea del planning norteamericano y las máximas del New Deal.

${ }^{20}$ En el Plan de desarrollo para la costa francesa sobre el Mediterráneo (la costa de Roussillon).
} 
Rausch. Planificación urbana e infraestructura en tiempos violentos: la ciudad de Santa Fe (Argentina) durante...

\section{Orden urbano, limpieza y crecimiento territorial armónico en el contexto del consenso antisubversivo: la politicidad del Plan Director}

Una lectura enfocada meramente en el documento que reúne las propuestas del PD podría conducir a considerar los diagnósticos y planteamientos de la propuesta como políticamente neutrales. La elaboración discursiva que se despliega en sus páginas apela a la descripción del espacio urbano santafesino a partir de datos objetivos -eminentemente cuantitativos- que definen una serie de problemas, cuya solución se encontraría en las acciones de ordenamiento, principalmente llevadas adelante a través de normativas. Sin embargo, aquí interesa destacar que los productos culturales y sociales no pueden ser desvinculados de las condiciones históricas específicas que constituyen su campo de posibilidad ${ }^{21}$, y por lo tanto, toda propuesta de transformación espacial, principalmente viniendo de una entidad estatal (en tanto producto cultural), consiste en una toma de posición política, donde la neutralidad -sea ésta estratégica o producto de acciones irreflexivas- no constituye más que una pretensión o idealización. Para el caso de estudio, y considerando que los años finales de la década de 1970 en Argentina se caracterizaron por acciones de violencia y terrorismo de Estado, dirigidas a eliminar la disidencia política, resulta cuando menos sospechoso el discurso pragmático y pretendidamente neutral que encontramos en el mencionado documento. Si bien, en sus inicios, el PD constituyó una deriva de las acciones del Ministerio de Planeamiento, en los últimos años de la década de 1970, pueden encontrarse elementos que nos permiten situarlo como una propuesta de la fracción politicista de la UDM, según la clasificación que ha aportado Canelo (2016). Siguiendo a la autora, esta fracción si bien acordaba con el consenso antisubversivo junto a las demás fracciones de la UDM, intentaba al mismo tiempo mantener el consenso social a través de una postura pragmática en el alcance de sus objetivos basada en el fortalecimiento de las municipalidades.

El PD se originó en las directrices impartidas por la Ley 16.964/66, ya que la Dirección de Planeamiento santafesina era un producto de los lineamientos que trazaba la misma al crear el SNPAD. Entre otras cuestiones, la ley establecía la finalidad del SNPAD (art. 2), creaba oficinas técnicas de planeamiento a cargo del Consejo Nacional de Desarrollo (CONADE) (art. 3) y asignaba en la figura del presidente, la máxima autoridad de la cual dependían todas las acciones de desarrollo nacional (art. 7). Asimismo, durante los primeros años de confección del PD, el exiguo equipo técnico de la DPUyPM (entre 5 y 6 técnicos) tenía vinculaciones con la Comisión Nacional Argentina de la Cuenca del Plata (CONCAP), perteneciente al Comité Intergubernamental de la Cuenca del Plata (CIC), cuya sede funcionaba en Buenos Aires ${ }^{22}$. Dicho comité se definía como "el órgano permanente de la Cuenca encargado de promover, coordinar y seguir la marcha de las acciones multinacionales encaminadas al mejor aprovechamiento de los recursos de la Cuenca del Plata y al desarrollo armónico y equilibrado de la región, en orden al

${ }^{21}$ El aporte de Michel Foucault (2002) a los estudios culturales en lo relativo a las formaciones históricas ha sido especialmente relevante en el enfoque adoptado en este trabajo, así como también la posterior lectura del filósofo que hace Gilles Deleuze (2013).

${ }^{22}$ Entrevistas realizadas a los arquitectos W. Giacomino y Luis Amavet (Asistente Técnico en Equipo Responsable Plan Director 1980). 
logro de los objetivos fijados por los cancilleres" (Kempeff Basigalupo, 1978, p.96). El CIC se constituyó formalmente el 1 de junio de 1967 integrado por funcionarios diplomáticos representantes de Argentina, Bolivia, Brasil, Paraguay y Uruguay. A través del Tratado de la Cuenca del Plata se pretendía plantear un esquema especial de integración para el desarrollo (Kempeff Basigalupo, 1978). Estas relaciones entre el equipo del PD y los organismos de escala más amplia que lo urbano, estaban dando cuenta de la voluntad de regionalización e internacionalización con la que se proyectaba el plan en el marco del SNPAD. Dichas vinculaciones quedarían plasmadas en las obras regionales que el plan promovía: 1) aprovechamiento integral del Paraná Medio a través del PHPM; 2) planificación integral de los bajos submeridionales; 3 ) aprovechamiento múltiple de los esteros del Iberá; y 4) canalización del río Bermejo (PD, 1980, pp.2627). Algunos de estos proyectos formaban parte de las obras programadas por el CIC pero tenía sus antecedentes en décadas anteriores ${ }^{23}$.

Con el inicio de la presidencia de Juan D. Perón, Giacomino dejó la dirección de planeamiento, y al poco tiempo, también lo hizo Nardi, ocupando la dirección Edgardo Gambini hasta la finalización del plan en plena dictadura militar. Los años que mediaron entre el ingreso de Gambini y los últimos años de la década de 1980 se nos presentan ausentes de registros documentales referidos a su evolución. Según una fuente entrevistada, la oficina técnica mermó sus actividades y entró en un letargo prolongado que fue postergando la finalización del mismo. La versión final tendría una combinación de las ideas pergeñadas en los primeros años, pero reformuladas con aportes de corte tecnocrático y normalizador, más acorde a las propuestas de la fracción politicista de la UDM, así como también a situaciones coyunturales de finales de la década de 1970.

Estos últimos años de finalización y aprobación del plan fueron parte de un momento histórico totalmente diferente a la primera época. Si bien el derrotero del PD -como se dijo antes- atravesaría diferentes gobiernos, coincidimos con Canelo (2016) cuando afirma que la UDM argentina tuvo características muy específicas respecto de las anteriores, y sobre las cuales interesa detenernos para comprender este instrumento urbanístico en su condición histórica y política. En efecto, uno de los objetivos básicos del consenso antisubversivo fue la instauración de una idea de orden y control, antagonizando con el caos atribuido a gobiernos anteriores, especialmente al peronismo. Dichos objetivos pueden observarse en las premisas del PD, así como también en diversos artículos de la prensa local santafesina -analizados por Citroni (2011)- que desde mediados de 1970 señalaban la necesidad de intervenciones urbanas con dicho fin. Esta autora ha destacado que las ideas de orden y limpieza intentaban establecer un pánico moral a través del cual se legitimaban las intervenciones del Estado en el espacio público $^{24}$. Para Citroni, durante la UDM en Santa Fe, se hizo coincidir una imagen

${ }^{23}$ El aprovechamiento del PM era una iniciativa del año 1957, y los antecedentes de la canalización del río Bermejo pueden remontarse a un proyecto que el ingeniero Henri entregó, en 1917, al gobierno nacional, y que comenzó a desarrollarse en la década de 1930, siguiendo a partir de ese momento, un derrotero con sucesivos incentivos e interrupciones (Lella, 1957, p. 50). Ambos proyectos nunca fueron concretados.

${ }^{24}$ La noción de pánico moral fue acuñada por el sociólogo Stanley Cohen y hace referencia a "los momentos en los cuales un grupo, condición o situación social, o un conjunto de acontecimientos, son considerados 
Rausch. Planificación urbana e infraestructura en tiempos violentos: la ciudad de Santa Fe (Argentina) durante...

de ciudad (caótica y anárquica) con una situación social análoga, y el pánico moral actuaba como legitimador del despliegue de diversos dispositivos "de control social y de ordenamiento territorial y social de las conductas" (Citroni, 2011, p.72).

Ahora bien, la idea de conjurar el caos -producto de los procesos de urbanización- puede observarse en las bases mismas de la disciplina urbanística. El control del espacio y el disciplinamiento social a través del ordenamiento territorial se encuentra en las preocupaciones del Urbanismo Moderno, y como ha sugerido Ballent (1993, p.16), las acciones de planeamiento requerían de un poder fuerte ${ }^{25}$. Además, conjurar el caos, como se vio antes, ya estaba en las premisas del planeamiento de la década de 1940 que difundía Pastor. Sobre éste, Ballent señaló la relación compleja que el arquitecto liberal tuvo con el peronismo, pero como dice la autora, "técnica y política compartían un imaginario, coincidían frecuentemente en sus utopías" (Ballent, 1993, p.19), y podríamos agregar, que dicho imaginario fue atravesando diferentes gobiernos y posiciones políticas sin cuestionamiento.

En este mismo sentido, el PD proponía alentar "un crecimiento ordenado y armónico" así como también lograr legitimación social a través de "propender al bienestar de sus habitantes", bienestar que se entendía en los términos de los valores promovidos por la dictadura, en su vocación refundacional: orden, homogeneización social y cohesión nacional ${ }^{26}$. Según lo expresaba el PD, dichas propuestas se concretarían "a través la transformación físico-espacial y del aprovechamiento de los recursos" (PD, 1980, p.-:11). Asimismo, el PD venía a regularizar y legitimar una serie de intervenciones urbanas que el gobierno municipal había proyectado en la ciudad desde hacía algunos años pero que tuvieron concreción a finales de la década de 1970. Tal es el caso de la peatonalización de la calle San Martín para acondicionarla como centro comercial y la posterior demolición, en 1980, del Mercado Central, ubicado originalmente a una cuadra de dicha peatonal. Iniciativas similares, y con la misma voluntad de expulsión de lo popular hacia zonas periféricas, mencionan Jajamovich y Menazzi (2012) para Buenos Aires durante el mismo período. Estas propuestas del PD se formulaban en plena coherencia con diversas regulaciones que el gobierno municipal había estipulado, como prohibiciones para construir ranchos y criar animales en zonas urbanas y obligaciones a los propietarios para la mantención de frentes, veredas y terrenos baldías, por ejemplo (Citroni, 2011).

Aún más, acorde con la premisa de ordenar la anarquía de la periferia urbana, el PD proponía una organización espacial del centro urbano consolidado (Ver Fig. 1, 3 y 4) que se conectaba con el área del albardón donde se encuentran ubicadas las localidades de la costa.

una amenaza para los valores e intereses de la sociedad en cuestión" (Citroni, 2011, p.71).

${ }^{25}$ En esta lógica de mediados de los 40, dicho poder fuerte se materializaba en acciones de planeamiento y venía a remediar el desorden provocado por la economía liberal (Ballent, 1993, p. 16).

${ }^{26}$ Puede observarse en el ideario de este gobierno, un sentido refundacional patriótico, que intentaba recuperar el proyecto de la Generación del 80, el cual a su entender, había sido interrumpido en la década de 1930, llevando al país a la decadencia cultural (Canelo, 2016). 
Figura 3: Esquema que muestra la idea-fuerza de expansión urbana hacia la $\operatorname{costa}^{27}$
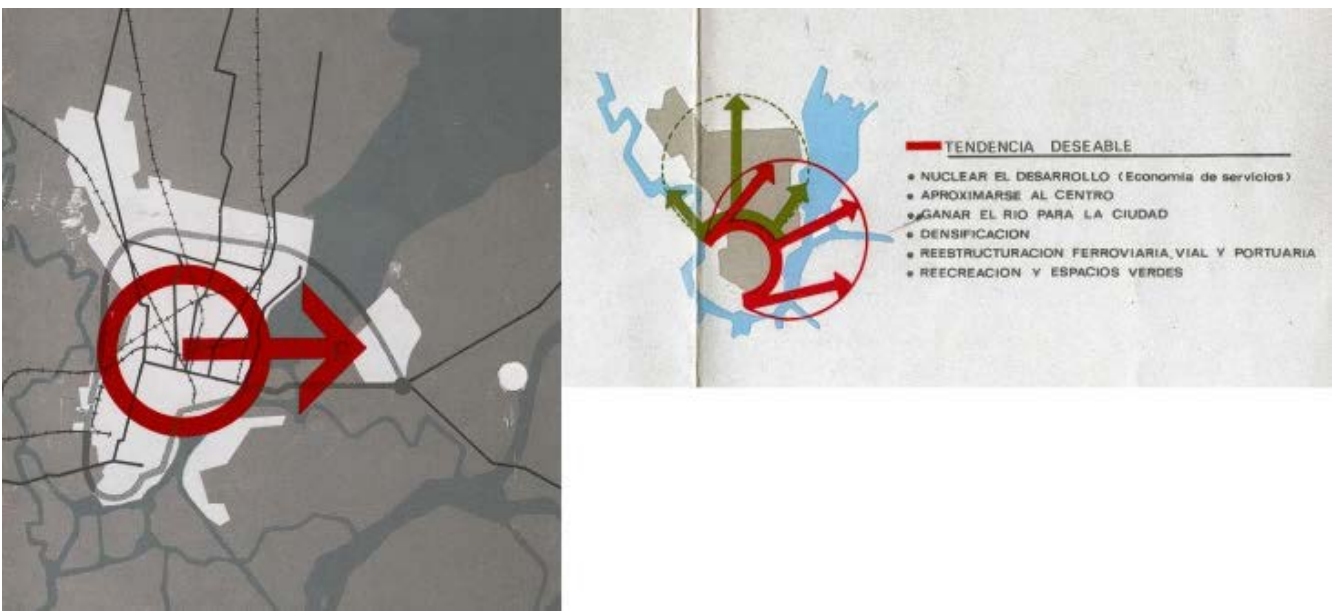

Fuente: MNS. Archivo de la Dirección de Planeamiento Urbano.

Figura 4: Directrices generales de ordenamiento ${ }^{28}$

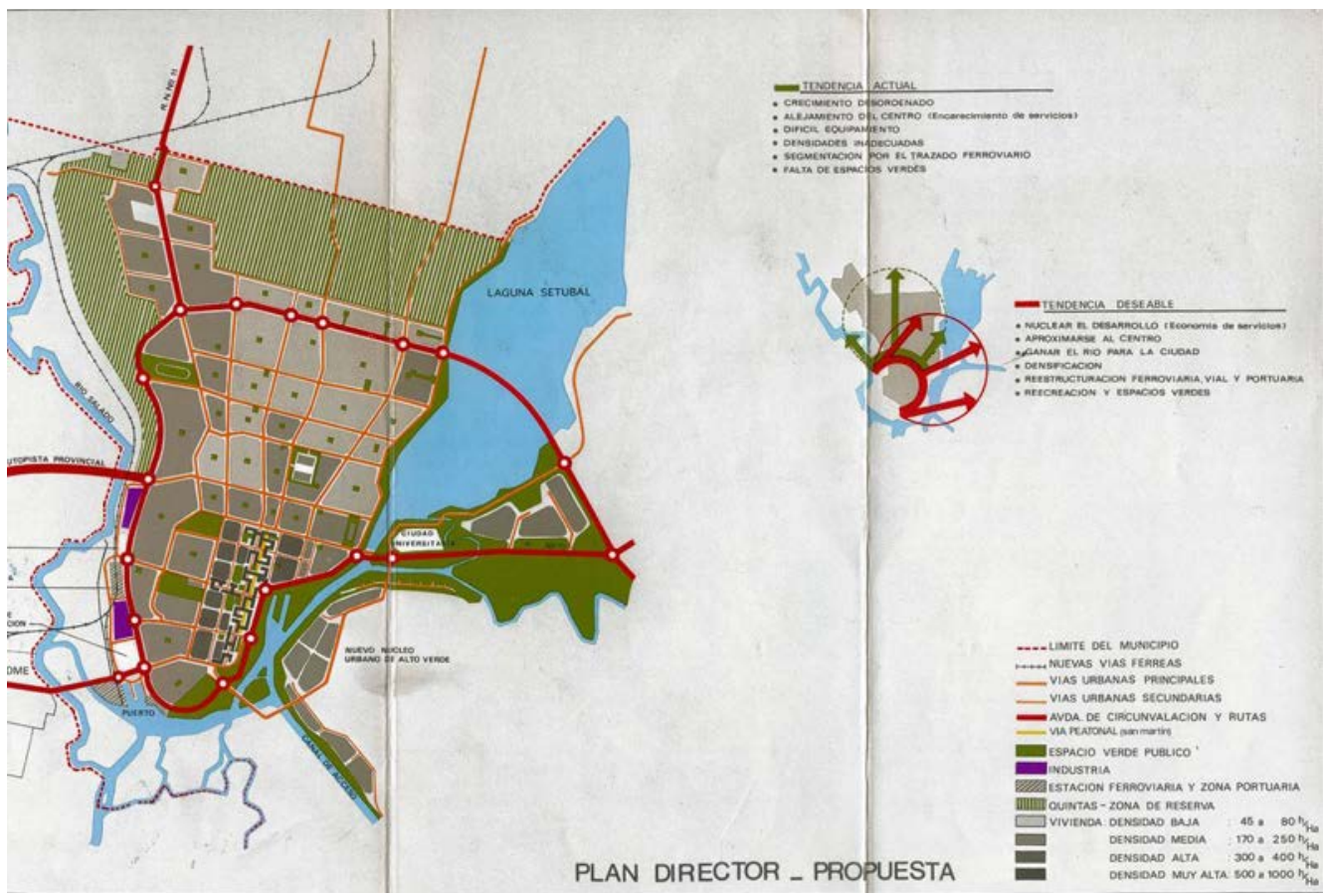

Fuente: MSF. Archivo de la Dirección de Planeamiento Urbano.

${ }^{27}$ En la Figura 3, esta idea-fuerza, puede verse concretada en el instrumento urbanístico.

${ }^{28}$ Los documentos de la Fig. 3 y 4 no poseen fecha pero se encontraron junto a otros en los que figura Nardi como director de Planeamiento Urbano y Conrado Puccio como intendente de la ciudad. De estos datos inferimos que la documentación data de entre 1969 y 1972 (período de la intendencia). 
Rausch. Planificación urbana e infraestructura en tiempos violentos: la ciudad de Santa Fe (Argentina) durante...

Esta área inundable conformada por las localidades Colastiné (Norte y Sur) y San José del Rincón, había sufrido desde 1960 un proceso de gradual loteamiento y ocupación residencial por la vía de la excepción ${ }^{29}$, el cual fue intensificándose hacia finales de la década de 1970. El PD aprovechaba el terraplén proyectado para la represa del Paraná Medio, ordenando y normalizando la urbanización del área (que hasta ese momento no tenía regulación) y definiéndola como zona suburbana: "Dicho sector ${ }^{30}$, presenta un tipo de asentamiento residencial de características suburbanas y de densidades de edificación y población muy bajas [...]. En lo que respecta a los terrenos comprendidos dentro del albardón costero, se verifica que los mismos han sufrido subdivisiones prematuras de tipo residencial de fin de semana [...]. De los terrenos urbanizados bajo y sobre Cota 15 IGM $^{31}$, que totalizan 1731 Has., se encuentran edificados 267 Has., lo que representa el $15 \%$ del total urbanizado, valores que expresan, por sí solo, la anomalía de un fraccionamiento excesivo e indiscriminado." (PD, 1980, p. 39).

Lo que el PD determinaba como anomalía refería al loteamiento del área sin una previa normalización y ordenamiento del proceso (incluso, urbanizaciones en áreas inundables). Por ese entonces, la costa estaba conformada por la coexistencia entre usos rurales (el PD describe explotación avícola, florícola, pastoreo, fábricas de ladrillos) y residenciales de fin de semana, sin una zonificación definida. Asimismo, el PD menciona "el problema de la propiedad y tenencia de la tierra" 32 (PD, 1980, p. 39), que a través del instrumento urbanístico se intentaba regularizar.

A partir del eje sur-norte constituido por la Ruta Provincial $\mathrm{N}^{\circ} 1$ que recorría la costa, el PD organizaba el territorio a través de una trama jerarquizada de calles internas y enlaces mayores de escala regional. Hacia el noreste, la misma ruta enlazaba con una conexión hacia el proyectado emprendimiento hidroeléctrico.

Puede verse que las premisas del planeamiento regional utilizadas por la UDM no difieren sustancialmente de las elaboradas por Pastor durante el mandato peronista. El curso fluvial como integrador de las propuestas urbanas, los enlaces ferro-viales estructuradores del territorio en la conformación de una región de planeamiento y la integración rural-urbana que se concreta en los dos elementos anteriores. Asimismo, el horror por las barriadas (que menciona Rigotti) puede verse materializado en algunas prescripciones del PD como la re-estructuración ferroviaria. Tal modificación era justificada de la siguiente manera: "El mayor inconveniente causado por la presencia de vías férreas dentro de la estructura urbana, es de orden social. Estas crean, no sólo

\footnotetext{
${ }^{29}$ En 1959 la Ordenanza municipal No 4772 anuló la Ordenanza municipal № 3864 del año 1939, que regulaba las urbanizaciones en esta zona. A partir del hecho, el área fue ocupándose sin un marco legal regulatorio.

${ }^{30}$ Haciendo referencia al sector de la costa (PD, 1980, p. 38).

${ }^{31}$ Cota por debajo de la cual el Instituto Geográfico Militar (IGM) determinó la inundabilidad de los terrenos.

${ }^{32}$ La costa constituyó, durante gran parte del siglo XX, el lugar de asentamiento para pescadores y población no incorporada al régimen de la propiedad. Muchos de ellos eran trabajadores en los cultivos. Asimismo, la característica periódicamente inundable de algunas áreas dificultaba su registro y regulación catastral, permitiendo loteos en área inundables. El PD también menciona venta de lotes "con anterioridad a la aprobación de la urbanización" (PD, 1980, p. 40).
} 
barreras de aislamiento e incomunicación en distintos barrios de la ciudad, sino que, al impedir en algunas zonas accesos normales, son un factor más para la localización y asentamiento de villas de deficientes condiciones de habitabilidad ${ }^{33}$ " (PD, 1980, p. 46). Más adelante, el documento mencionaba "los basurales y yuyales que existen en las zonas aledañas a las vías férreas" (PD, 1980, p. 46), las cuales era necesario -según el plan- eliminar. En términos políticos, puede decirse que al autoritarismo de la UDM le fue particularmente útil la dicotomía caos/orden en su estrategia política para establecer una línea de ruptura con la gestión anterior -incluso con los gobiernos militares precedentes- y justificar así sus acciones de represión y expulsión (así como también de desaparición) de sectores sociales considerados subversivos. De este modo, al caos atribuido a la gestión política anterior (el peronismo), se lo conjuraba -violentamente- a través de las ideas de orden y limpieza del territorio y del espacio urbano municipal, pero también limpieza de personas y de ideas consideradas subversivas.

\section{Desarrollo nacional, independencia energética y hegemonía geopolítica: el proyecto hidroeléctrico Paraná Medio}

El PHPM fue inicialmente una propuesta ${ }^{34}$ del gobierno dictatorial de Pedro Aramburu (1955-1958) en el marco de la autodenominada Revolución Libertadora ${ }^{35}$. Este gobierno intentó establecer un fuerte antagonismo político con el precedente, si bien en materia de políticas económicas la historiografía mantiene posiciones divergentes respecto de la efectiva existencia de dicha ruptura ${ }^{36}$. El emprendimiento hidroeléctrico se propuso como parte de las recomendaciones que había realizado Raúl Prebisch ${ }^{37}$-convocado por Aramburu- en un informe sobre la situación económica del país (Prebisch, 1955). En el mismo, el director de la CEPAL planteaba la necesidad de reforzar las políticas de sustitución de importaciones impulsando al sector industrial y abrir la economía argentina a los capitales externos. En este marco, el PHPM se presentaba como una obra prioritaria para el desarrollo industrial del área central del país, a través de la provisión energética.

El inicio de la presidencia de Arturo Frondizi ${ }^{38}$ en 1958 interrumpió los trabajos de prefactibilidad del proyecto que se venían realizando, ya que este gobierno -continuando con el modelo económico de sustitución de importaciones- decidió priorizar el desarrollo industrial de la región Comahue (Azcoitía y Nuñez, 2014). El

${ }^{33}$ Debe tenerse en cuenta que en plena persecución por parte de la dictadura de las facciones políticas disidentes, estos espacios fuera del control estatal funcionaban como refugios de los perseguidos.

${ }^{34}$ PEN. Decreto ley $N^{\circ} 14.467$, del 5 de setiembre de 1958.

${ }^{35}$ Dictadura militar establecida luego del golpe de Estado efectuado al gobierno peronista en 1955.

${ }^{36}$ Algunos historiadores marcan la ruptura con las políticas económicas del peronismo (Muro de Nadal, 1997; Ferrer, 2004 y Rapoport, 2000), mientras que otros destacan que no existieron variaciones sustanciales en las medidas económicas (Gernuchoff y Llach, 1997).

${ }^{37}$ Académico y economista argentino, Secretario Ejecutivo de la CEPAL entre 1950-1963. Sus aportes se reconocen en el campo de la teoría económica denominada estructuralista y los estudios del desarrollo económico.

${ }^{38}$ Presidente argentino entre 1958-1962 del partido Unión Cívica Radical, y la posterior división en Unión Cívica Radical Intransigente. 
Rausch. Planificación urbana e infraestructura en tiempos violentos: la ciudad de Santa Fe (Argentina) durante...

plan de desarrollo que iría a retomar el PHPM (y otras obras hidroeléctricas) fue el Plan Nacional de Desarrollo y Seguridad 1971-1975 (PNDyS). Allí quedó expresada la intención del gobierno dictatorial presidido por Alejandro Lanusse (1971-1973), de impulsar medidas para el aprovechamiento de los recursos hídricos. El PNDyS consideraba a la energía hidráulica como un elemento clave para el desarrollo nacional ${ }^{39}$ e incorporaba la idea de desarrollo regional. Esta última se expresaba, por un lado, en su intención de dar continuidad a los objetivos de regionalización planteados en el momento de institucionalización del SNPAD, y por el otro, en el segundo objetivo del mismo plan, que señalaba "promover la integración nacional mediante un desarrollo regional armónico y más equilibrado" (p. 138). La documentación del emprendimiento hidroeléctrico, al igual que el PD, se hacía eco de las ideas del planeamiento regional de la década de 1940 en sus objetivos de coherencia espacial, integración regional, equilibrio territorial e interés público ${ }^{40}$.

A pesar de tales intenciones por impulsar la obra hidroeléctrica, no es hasta 1976 que el gobierno nacional toma acciones efectivas, encomendado a la empresa estatal Agua y Energía como encargada de llevarlo adelante. En 1978 fue contratada la asistencia técnica de Technopromexport ${ }^{41}$, una empresa soviética que se encargaría de los estudios de prefactibilidad, del asesoramiento técnico y de la provisión de tecnología. Por ese entonces, el gobierno argentino mantenía relaciones comerciales con la URSS, principalmente en torno a la exportación de cereales frente al bloqueo que EEUU sostenía con el país europeo ${ }^{42}$ (Gilbert, 1994; Fuentes, 2005).

La obra propuesta consistía en un embalse que abarcaba el tramo medio del río Paraná (Fig. $3^{43}$ ) desde Goya (Corrientes) donde se encontraba el cierre denominado Patí, hasta Villa Urquiza (Entre Ríos) atravesando la isla Chapetón, donde se encontraba el cierre con el mismo nombre. Este último cierre fue el desarrollado proyectualmente por Agua y Energía durante la UDM (ver Fig. 5). Además del cierre frontal con central hidroeléctrica, poseía un cierre lateral que recorría más de $200 \mathrm{~km}$ la orilla santafesina (ver Fig. 6). Se conformaba así un terraplén de contención que cerraba con la barranca entrerriana.

\footnotetext{
${ }^{39}$ De las 8 represas nacionales de mayor dimensión, seis comenzaron a construirse entre finales de la década de 1960 y principios de 1980. Respecto de las binacionales, Salto Grande fue construida en los mismos años, siendo más tardía Yacyretá, cuya primera iniciativa data de 1957, aunque la obra fue iniciada en la década de 1980.

${ }^{40}$ Dichas ideas no se efectivizaron ni se articularon en la propuesta de la represa. La prolífica producción documental de Agua y Energía en torno al emprendimiento muestra un interés centrado en las cuestiones técnicas asociadas a la producción de energía y al cálculo de las inversiones, siendo muy escasas las definiciones proyectuales (sólo referencias generales y vagas) respecto del desarrollo regional y del ensamblaje represa-proyectos complementarios-región.

${ }^{41}$ PEN. Decreto ley No 2.648, del 6.11.1978.

${ }^{42}$ Gilbert (1994, p. 342) señala que la URSS, "presionada por la política de Carter" (que manejaba los excedentes según una política de derechos humanos) no tuvo alternativa a importar de la dictadura argentina. Según el autor, en 1978 las exportaciones argentinas a la URSS en cereales ascendió a 312 millones de dólares contra los 89 millones del año anterior.

${ }^{43}$ La publicación no tiene fecha y por su contenido ha podido deducirse que es posterior a 1978.
} 
Figura 5: Planos de ubicación de embalse

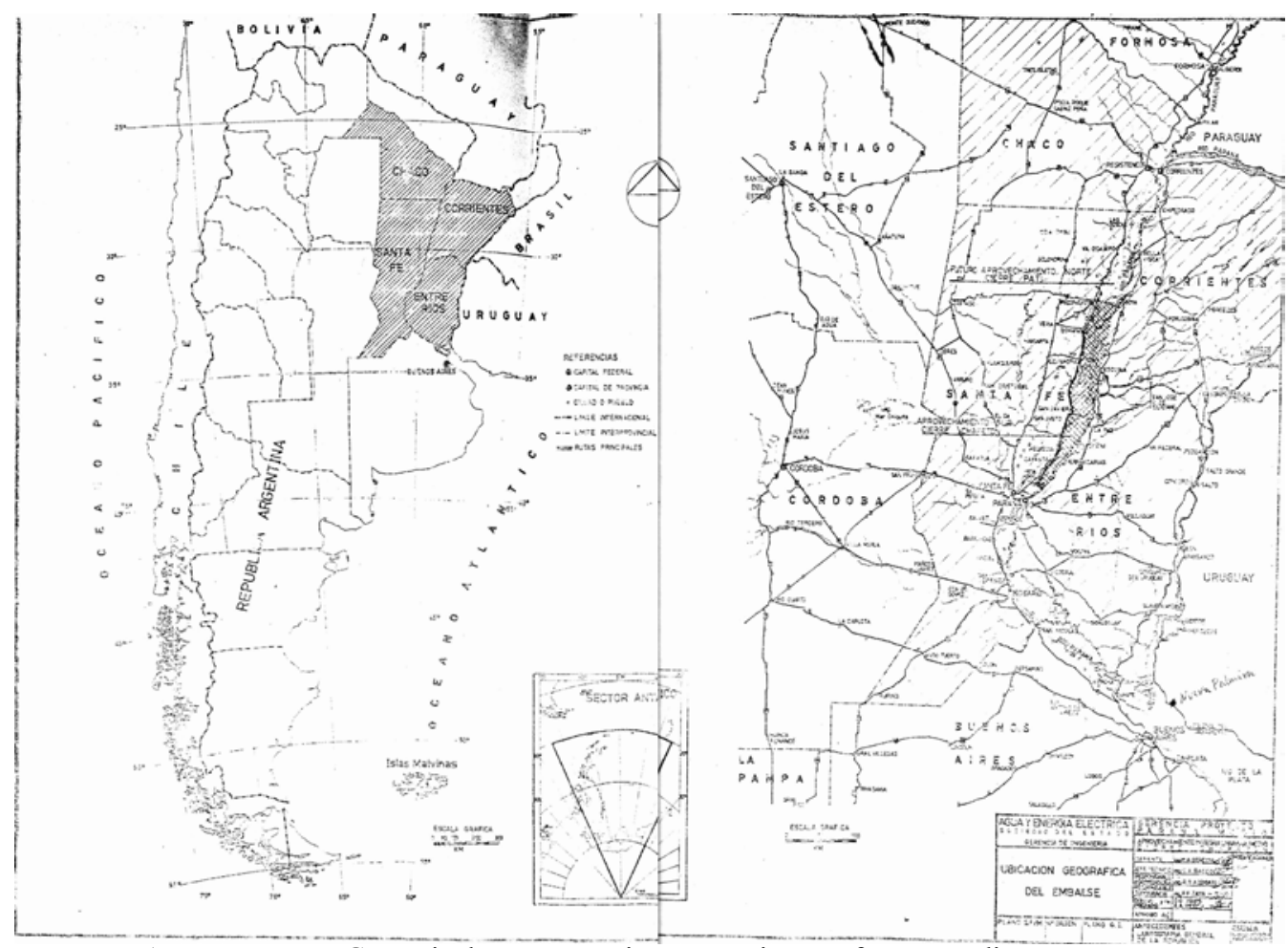

Fuente: Agua y Energía. Gerencia de Programación e Ingeniería. Jefatura estudios y Proyecto Paraná Medio. Aprovechamiento Paraná Medio, Ubicación Geográfica de embalses. Argentina, 1976. Plano nº4, ord.4. Plano DEP 22356.

Según los informes técnicos de AyE, cada central hidroeléctrica contaba con $3000 \mathrm{GW}$ de potencia y pretendía generar hacia finales de la década de 1970, una energía media anual (E.M.A.) de $18535 \mathrm{GW} / \mathrm{h}$.

El PHPM puede considerarse una de las propuestas más emblemáticas del ideario desarrollista-nacionalista de la segunda mitad del siglo XX, asociado a las ideas de independencia energética y progreso económico, en el marco de las políticas económicas orientadas a la industrialización que adoptaron los diferentes gobiernos entre 1950 y 1970. Su ubicación geográfica era considerada estratégica dentro del esquema de integración propuesto en el Tratado de la Cuenca del Plata y fue apreciado como "uno de los proyectos principales" (Camba, 1979, p. 38) dentro de la misma. Con la construcción de la obra se intentaba conformar un polo de desarrollo en el área central de Argentina; y en particular, conectar a la ciudad de Santa Fe internacionalmente a través de la salida al océano Atlántico. En el esquema de organización territorial propuesto por el PD, el emprendimiento hidroeléctrico funcionaba como un nodo infraestructural energéticoconector de escala regional e internacional. 
Rausch. Planificación urbana e infraestructura en tiempos violentos: la ciudad de Santa Fe (Argentina) durante...

Figura 6: Trazado de los cierres y embalse

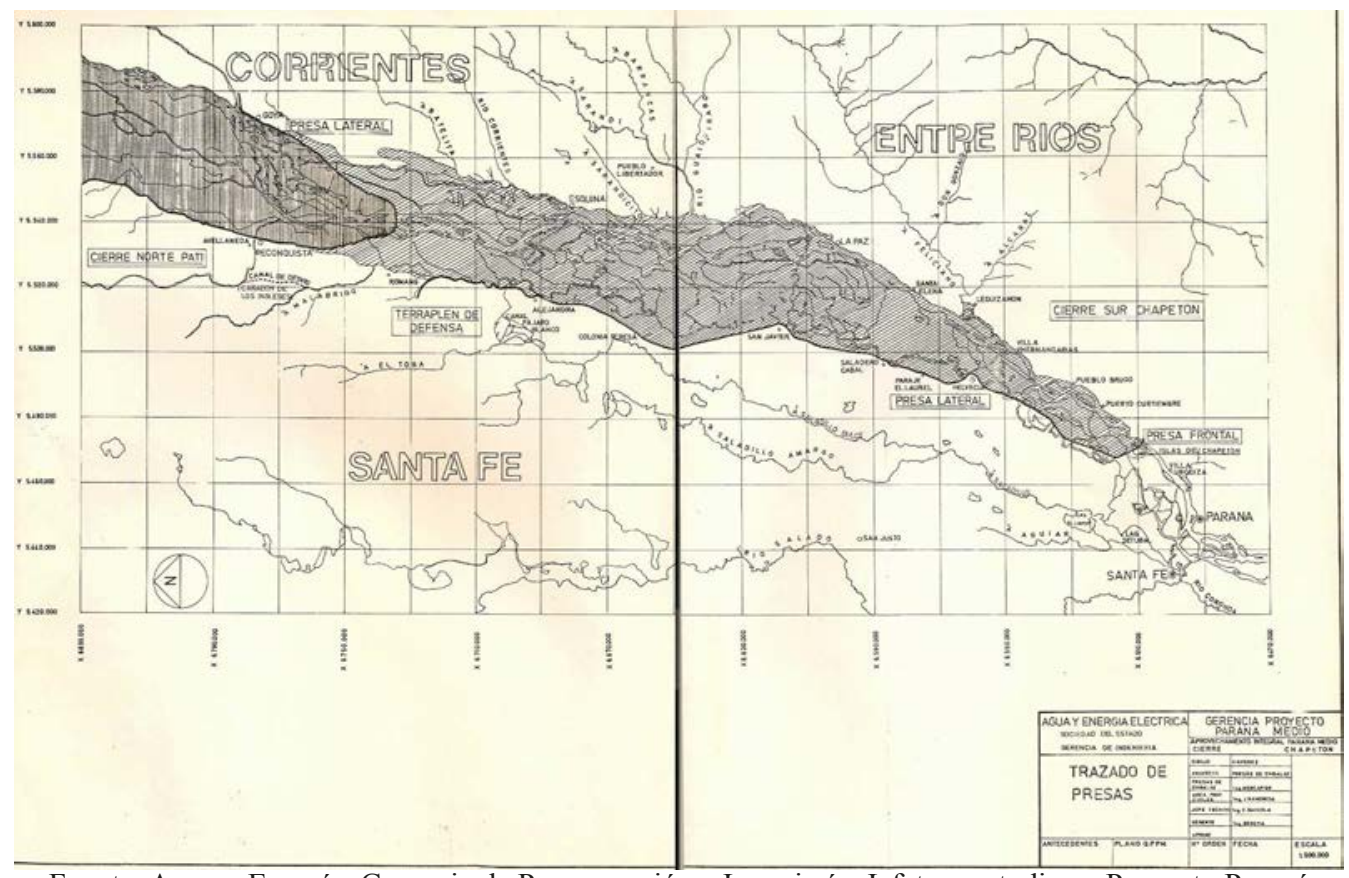

Fuente: Agua y Energía. Gerencia de Programación e Ingeniería. Jefatura estudios y Proyecto Paraná Medio. Aprovechamiento Paraná Medio, Trazado de Presas, Argentina, 1976.

A pesar de las interrupciones en el desarrollo del proyecto -vinculadas principalmente a dificultades para su financiación-, tanto las ideas que lo sustentaron y legitimaron, como la propuesta técnica y de organización territorial, permanecieron sin modificación durante medio siglo. La idea de desarrollo nacional asociada a las infraestructuras energéticas, y en particular a la hidráulica, se mantuvo indiscutida la mayor parte del siglo XX. El paradigma hidráulico se presentaba como un conjunto de saberes, que incluía tanto elementos discursivos como soluciones técnicas, y que pretendía resolver determinados problemas, como la irrigación de áreas para la expansión de la agricultura, el crecimiento de las urbanizaciones, la necesidad de independencia energética y el aumento de la industrialización, entre otros, asegurando al mismo tiempo, la soberanía energética del país ${ }^{44}$ y sobre sus recursos naturales. La consideración del agua como un recurso abundante -incluso ilimitado- junto a los objetivos de crecimiento económico y poblacional que orientaron las políticas públicas durante ese período en América Latina, hicieron de la infraestructura hidráulica un símbolo del desarrollo (Brunstein, 1987; Kaika, 2006; Azcoitía y Nuñez, 2014; Rausch, 2016; Hanna y Allouche, 2018).

Pero más allá de la amplia legitimación en el tiempo que tuvo el proyecto, concebido como una pieza técnica al servicio del desarrollo, nos interesa destacar el rol estratégico de orden político-ideológico que la obra tuvo durante la UDM. En efecto,

${ }^{44}$ De especial interés hacia la década de 1970, en medio de la llamada crisis del petróleo. 
desde 1976 la promoción del emprendimiento puede observarse orientada a crear consenso social en torno a algunas aspiraciones del gobierno dictatorial, en particular de la fracción dura del mismo (la cual entre 1976 y finales de 1977 tuvo la dirigencia del Ministerio de Planeamiento - MP) $)^{45}$. Y a pesar de que en 1978 se diera un giro liberal en el gobierno (concretado en el fortalecimiento de Martínez de $\mathrm{Hoz}^{46}$ ) junto a la transformación, en noviembre de 1978, del MP en una Secretaría dependiente de la presidencia, las ideas del ala dura y sus propuestas nacionalistas pervivieron a través del tiempo. En una conferencia brindada en la ciudad de Santa Fe en el año $1979^{47}$, el almirante Armando Lambruschini ${ }^{48}$ (1979) expresaba "la urgente necesidad nacional de ocupar decididamente nuestros espacios vacíos” (p. 27), destacando la importancia de la Cuenca del Plata como vía de transporte y espacio en el cual "debió haberse ya realizado el desarrollo de la región, la conquista y la incorporación de tierras a la cultura occidental y al mundo cristiano" (p. 28); y sigue: "Este eje norte-sur, no solamente debe ser consolidado, sino que debe ser expandido, afincando intereses que además de ser lícitamente respetables, contribuyan al fortalecimiento de nuestra nacionalidad" (p. 28).

Según ha sugerido Canelo (2016, p. 76), el plan político de los duros consistía en "volver irreversible la intervención militar", y para ello -dice la autoraera imprescindible construir consenso social y crear un nuevo sistema político. De ahí, el objetivo refundacional que tuvo la UDM. Tal como desarrolla la autora, en el documento elaborado en 1977 por el MPyAD, que pretendió ser la base ideológica de este gobierno y fue denominado Proyecto Nacional ${ }^{49}(\mathrm{PN})$, se señalaba una situación de crisis nacional como consecuencia del desplazamiento de las elites del pensamiento y su reemplazo por la sociedad de masas. Dicho desplazamiento -en la visión del gobiernohabía conducido a la descomposición total de la vida republicana (PN, 1977, p. 90 citado en Canelo, 2016). De este modo, la UDM se posicionaba en la función de refundar la Nueva República sustentada "en los valores del Ser Nacional” (PN, 1977, p. 321 citado en Canelo, 2016, p. 77).

En tal contexto, el PHPM puede considerarse una pieza relevante para legitimar las ideas del PN de Diaz Bessone, cumpliendo asimismo con funciones geoestratégicas dentro del imaginario de guerra que se intentaba difundir. En palabras de De Nevares (miembro del ejército), el PHPM venía a conformar un área pivote orientada a la integración nacional, junto con la "neutralización de la presión extranjera sobre el Noreste" (De Nevares, 1978). Por su parte, Lambruschini (1979, p. 30) aseguraba

${ }^{45}$ El ministro designado fue Ramón Díaz Bessone, a quién Canelo (2016) considera un "duro". Díaz Bessone también había participado en la elaboración del PNDyS 1971-75.

${ }^{46}$ Ministro de Economía argentino durante el gobierno de la UDM. Sus políticas económicas se caracterizaron por la ortodoxia liberal y la eliminación de los controles de precios por parte del Estado.

${ }^{47}$ Esta conferencia formó parte de las "Segundas Jornadas El Paraná Medio", un evento realizado en Santa Fe en 1979, en el que participaron miembros de las Fuerzas Armadas, académicos e ingenieros. Las jornadas estuvieron organizadas por la Universidad Nacional del Litoral.

${ }^{48}$ Miembro de la Junta militar y Comandante en Jefe de la Armada.

${ }^{49}$ Este documento, a tono con el desarrollismo nacionalista y las ideas plasmadas en la Ley $\mathrm{N}^{\circ} 16964$ que dio nacimiento al SNPAD, no tuvo amplia aceptación entre los militares y confrontaba profundamente con las ideas económicas liberales que se estaban implementando. 
Rausch. Planificación urbana e infraestructura en tiempos violentos: la ciudad de Santa Fe (Argentina) durante...

acerca de las obras proyectadas: "Una política que merezca el nombre de tal para el área, debe apuntalarse en un verdadero arco de complejos hidroeléctricos, cuyo núcleo es precisamente el PHPM y cuyos extremos deberán apoyarse en el oeste en el Proyecto del Bermejo, y en el este en el Proyecto del Iberá"; y finalizaba su discurso apelaba a la idea del ser nacional: "Aquí estamos, no sólo ante una gran obra hidroeléctrica, ante un capítulo esencial de la concepción geopolítica de la Cuenca del Plata, sino ante un aprueba, una oportunidad para demostrar esa determinación de ser y de ser mejores" (Lambruschini, 1979, p. 34).

Puede observarse en la discursiva de gran parte de los promotores del PHPM una serie de ideas tales como la expansión estatal sobre el territorio, el estado como factor impulsor del desarrollo y la unidad nacional, que antagonizaban con las intenciones aperturistas de la fracción liberal. En este sentido, los objetivos del PN, y como consecuencia el descomunal gasto público que implicaba la construcción del PHPM, entraban en directo conflicto con los intereses de las demás fracciones de la dictadura, orientados al ajuste estatal, la privatización de empresas públicas y la liberalización de la economía. El rimbombante y ferviente despliegue concretado en eventos y publicaciones diversas que llevaron adelante los duros para promocionar el PHPM entre 1978 y 1979 puede comprenderse, en parte, desde una actitud defensiva (de sus intereses) y legitimadora de la ideología desarrollista-nacionalista la cual, hacia esos años, se encontraba en pleno declive dentro de los cuerpos gubernamentales. Pero, asimismo, dicho despliegue discursivo que vinculaba las ideas de nación, soberanía, ocupación territorial y refundación nacional puede comprenderse en el contexto más amplio de, por un lado, la guerra interna que la UDM llevó adelante contra los grupos políticos disidentes y cuyo objetivo fue la eliminación de aquello considerado subversivo, y por el otro, las disputas con Chile por islas en el canal de Beagle ${ }^{50}$ que alcanzaron un ánimo de guerra hacia 1978. La no concreción de la obra hidroeléctrica puede asimismo comprenderse históricamente en un momento donde, tanto las ideas que lo sustentaban, como las medidas necesarias para llevarlo adelante, se encontraban en franco retroceso en el nuevo contexto de apertura de los mercados y de hegemonía ideológica del Fondo Monetario Internacional, entidad que comenzaría a marcar el ritmo unívoco de las políticas económicas en los países de América Latina ${ }^{51}$.

\section{Conclusiones}

El análisis presentado no ha tenido como finalidad colocar en tela de juicio las funciones más específicas de los instrumentos de ordenamiento territorial y de las grandes infraestructuras, sino más bien destacar una serie de cuestiones vinculadas a

\footnotetext{
${ }^{50}$ Litigio argentino-chileno por la delimitación territorial en el canal, iniciado en el siglo XIX pero que tomó especial intensidad durante la UDM. Luego de un arbitraje a favor de Chile, en 1978, el gobierno militar argentino decidió invadir las islas en cuestión. Una mediación de la autoridad del Vaticano, Juan Pablo II, evitó la guerra entre los países. Un recorrido documentado por el conflicto puede verse en: Rossi de Flory, 1984.

${ }^{51}$ El año 1978 también marcaría el cese de las relaciones comerciales con la URSS y, por lo tanto, la desfinanciación del PHPM.
} 
su condición histórica y política que consideramos escasamente tenidas en cuenta en las oficinas técnicas gubernamentales, en las cuales se formulan los grandes proyectos. Retomando lo que se planteaba al inicio del artículo, nuestra intención fue evidenciar, a partir de dos casos, los modos generales y específicos en que los objetos técnicos han sido concebidos por el pensamiento moderno, y en particular por la ideología desarrollista, en su condición de políticamente neutrales y ahistóricos. La atribución de ambas condiciones no se encuentra explícita, pero se extrae del hecho de que estos proyectos no se modifican en los sucesivos gobiernos y se promueven con los mismos valores, tales como progreso, crecimiento económico y desarrollo nacional. Estos valores fueron compartidos por los distintos gobiernos argentinos desde la década de 1940 hasta mediados de los $80 \mathrm{~s}$, y han posibilitado que dichos proyectos fueran impulsados -sin cuestionamientos- desde muy distintas líneas políticas, incluso antagónicas.

Así pudo observarse que los planteamientos del primer referente del planeamiento regional en Argentina, José Pastor fueron desarrollados en las propuestas de ordenamiento territorial y en la legislación urbana del PD. Las directivas de Pastor acerca de ordenar el caos en un sistema urbano coherente, de aprovechar las cuencas fluviales para superar la actitud pasiva sobre los recursos naturales y de limpiar las barriadas armonizando las áreas rurales con las urbanas, se encuentran presentes en las propuestas espaciales del PD. Mientras que el PHPM se presentaba como una pieza central de aprovechamiento del río Paraná, orientada a la conformación de un polo de desarrollo.

Ahora bien, destacando la condición histórica e intensamente política de los objetos técnicos, y volviendo la mirada sobre las apropiaciones y estrategias que determinados grupos sociales realizan para establecer específicas relaciones de poder -en este caso la UDM argentina-, puede decirse que en los casos analizados, ambas condiciones quedaron manifiestas en las particulares apropiaciones (simbólicas y materiales) que llevó a cabo la dictadura sobre estos dos proyectos que tenían larga data. Y así como el PD se establecía como la pieza normativa y tecnocrática que re-establecía el orden y limpiaba el territorio de elementos populares y subversivos, el PHPM se alzaba como bandera de guerra de la fracción estatista, antiperonista y cristiana del gobierno dictatorial, la cual -como pudo verse- se encontraba por esos años en franco conflicto a nivel interno y externo.

\section{Referencias bibliográficas}

Antier, G. (2013) "La gestión del Planeamiento Regional en Île-de-France. Algunas reflexiones sobre las tendencias del planeamiento metropolitano". Urban, 5, pp. 14-23.

AzcoItía, A. y Nuñez, P. (2014). "Las represas hidroeléctricas de la región Comahue: expectativas de un desarrollo parcial”. Agua y Territorio, 4, pp. 12-22.

Ballent, A. (1993) "Los arquitectos y el peronismo. Relaciones entre técnica y política, Buenos Aires 1946-1955". Seminario de crítica, 41. Buenos Aires: Instituto de Arte Americano e Investigaciones Estéticas. 
Rausch. Planificación urbana e infraestructura en tiempos violentos: la ciudad de Santa Fe (Argentina) durante...

Brunstein, F. (1987) "Las grandes inversiones públicas y el problema del desarrollo regional". En Rofman, Alejandro; et. al. (Coords.) Los grandes proyectos y el espacio regional. Presas hidroeléctricas y el sistema decisional. Cuadernos del CEUR, 19, 1987; pp. 7-41.

Camba, F. (1979) “Aspectos Ferro-viales”. En Segundas Jornadas El Paraná Medio. Santa Fe: UNL, pp. 37-41.

Canelo, P. (2016) La política secreta de la última dictadura argentina (1976-1983). Buenos Aires: Edhasa.

Christaller, W. (1966) Central Places in Southern Germany. New Jersey: Prentice Hall.

Citroni, J. (2011) "Modos de control del espacio urbano en un contexto de poder autoritario. El caso de Santa Fe, Argentina, 1976-1981". Asuntos Urbanos Internacionales, 24, pp. 70-81.

Deleuze, G. (2013) El Saber. Curso sobre Foucault, tomo I. Buenos Aires: Cactus.

De Nevares, M. (1978) “El Paraná Medio en la Cuenca del Plata”. Realidad Económica, 32 , pp.18-24.

Escobar, A. (2007) La invención del Tercer Mundo. Construcción y deconstrucción del desarrollo. Caracas: El perro y la rana.

Ferrer, A. (2004) La economía argentina. Desde sus orígenes hasta principios del siglo XXI. Buenos Aires: Fondo de Cultura Económica.

Foucault, M. (2002) Las palabras y las cosas. Una arqueología de las ciencias humanas. Buenos Aires: Siglo XXI.

Fuentes, V. (2005) "La relación bilateral Argentina-Rusia: más que socios comerciales". En: Segundo Encuentro Centro de Reflexión en Política Internacional "Prospectivas y perspectivas de nuestra política exterior", IRI, 1 de setiembre.

Gernuchoff, P. y Llach, L. (1997) El ciclo de la ilusión y el desencanto: un siglo de políticas económicas argentinas. Buenos Aires: Ariel.

Gilbert, I. (1994) El oro de Moscú. Historia secreta de la diplomacia, el comercio y la inteligencia soviética en la argentina. Buenos Aires: Planeta.

Graham, S. y Marvin, S. (2001) Splintering Urbanism. Networked infrastructures, technological mobilities and the urban condition. London \& New York: Routledge.

Gutiérrez, J. J. (2016) "Del urbanismo al planeamiento: Pastor en la revista de Arquitectura (1943-1951)", Arquitectura del Sur, 34 (50), pp. 40-51.

Hanna, R. y Allouche, J. (2018) "Water nationalism in Egypt: State-building, nationmaking and Nile hydropolitics". En Menga, F. y Swyngedouw, E. Water, Technology and the Nation-State. London \& New York: Routledge, pp. 81-95.

Harvey, D. (1982) The Limits to Capital. New York: Oxford University Press.

Jajamovich, G. y Menazzi, L. (2012) "Políticas urbanas en un contexto de dictadura militar. Algunos interrogantes a partir de Buenos Aires (1976-1983)". Bitácora Urbano Territorial, 1 (29), pp. 11-20.

Kaika, M. (2006) "Dams as symbols of Modernization: Urbanization of Nature between Geographical Imagination and Materiality". Annals of the Association of American Geographers, 96 (2), pp. 276-301.

Kempeff Bacigalupo, R. (1978) "Proceso de Integración de la Cuenca del Plata”. Revista de Política Internacional, pp. 93-106. 
Kullock, D. (2010) "Planificación urbana y gestión social. Reconstruyendo paradigmas para la actuación profesional". Cuaderno Urbano. Espacio, cultura, sociedad, 9 (9), pp. 243-274.

Lambruschini,A. (1979) “Alocución del Señor miembro de la Junta Military Comandante en Jefe de la Armada, Almte. Armando Lambruschini”. En Segundas Jornadas El Paraná Medio. Santa Fe: UNL, pp. 27-34.

Lella, P. (1957) El aprovechamiento del río Bermejo como recurso fundamental para el desarrollo demográfico y económico del norte argentino. Tesis Doctoral. Facultad de Ciencias Económicas, Universidad de Buenos Aires.

Mattelart, A. (1996) The invention of communication. Minneapolis MN: University of Minnesota Press.

Mazza, C. (2008) "De lo sublime a lo técnico. La incorporación de la noción de paisaje en el planeamiento regional en Argentina". Perspectivas Urbanas/Urban Perspectives, 9, 51-64.

Muro de Nadal, M. (1997) 50 años de historia económica argentina (1946-1996): una síntesis de sus principales características. Buenos Aires: Sauce Grande.

Pastor, JM. (1947) Urbanismo con Planeamiento, principios de una nueva técnica social. Buenos Aires: Arte y Técnica.

Perroux, F. (1955) "Note sur la notion de pôle de croissance". Économie appliqué, 8, pp. 307-320.

Perroux, F. (1988) “The pole of development's new place in a general theory of economic activity”. En B. Higgins, \& D. Savoie, Regional economic development: essays in honour of François Perroux. London: Unwin Hyman, pp. 148-191.

Novick, A. y Piccioni, R. (1998). "Carlos María Della Paolera o la Amnesia del Urbanismo Argentino". Anales del Instituto de Arte Americano e Investigaciones Estéticas "Mario J. Buschiazzo", 30, pp. 112-149.

Prebisch, R. (1955) La situación económica del país. Buenos Aires: Presidencia de la Nación.

Rausch, G. (2010) "El Plan del 80 en Santa Fe: regionalización tardía ante una suburbanización inminente”. Cuaderno Urbano: espacio, cultura, sociedad, 9, pp. 111-129.

Rausch, G. (2013) "Dos visiones sobre la planificación regional en el final del auge desarrollista: la propuesta de orientación del crecimiento urbano (Santa Fe, Argentina, 1980)". Estudios Socioterritoriales, 14, pp. 133-158.

Rausch, G. (2016) "Agua, desarrollismo y emergencia del conflicto ambiental: el proyecto hidroeléctrico Paraná Medio en Santa Fe, Argentina 1957-1997’. Agua y Territorio, 7, 139-151.

Rapoport, M. (2003) Historia económica, política y social de la Argentina (1880-2000). Buenos Aires: Macchi.

Rigotti, A. M. (2003) Las invenciones del urbanismo en Argentina (1900-1960). Inestabilidad de sus representaciones científicas y dificultades para su profesionalización, Tesis Doctoral. Facultad de Arquitectura Planeamiento y Diseño, Universidad Nacional de Rosario. 
Rausch. Planificación urbana e infraestructura en tiempos violentos: la ciudad de Santa Fe (Argentina) durante...

Rigotti, A. M. (2004) José Pastor y la invención del planeamiento en Argentina. CURDIUR, Universidad Nacional de Rosario.

Rist, G. (2008) The History of Development. From Western Origins to Global Faith. London \& New York: Zed Books.

Rossi de Flory, M. L. (1984). Argentina y Chile en la zona del Beagle. Buenos Aires: Ministerio de Educación y Justicia.

Rostow, W. (1960) The Stages of Economic Growth: A Non-Communist Manifesto. Cambridge: Cambridge University Press.

Sachs, W. (2010) The Development Dictionary. A guide to knowledge as power. London: Zed Books.

\section{Otras fuentes}

Agua y Energía (1978) Aprovechamiento Integral Paraná Medio. Santa Fe: impresión oficial. Agua y Energía. Gerencia de Programación e Ingeniería. Jefatura estudios y Proyecto Paraná Medio. Aprovechamiento Paraná Medio, Ubicación Geográfica de embalses. Argentina, 1976. Plano nº 4, ord.4. Plano DEP 22356.

Agua y Energía. Gerencia de Programación e Ingeniería. Jefatura estudios y Proyecto Paraná Medio. Aprovechamiento Paraná Medio, Trazado de Presas, Argentina, 1976.

Entrevista al Arq. Luis Amavet; Asistente Técnico en Equipo Responsable Plan Director 1980. Entrevista al Arq. Waldemar Giacomino; Director en la Dirección de Planeamiento Urbano y Proyectos (1966-1969).

Ministerio de Planeamiento. Proyecto Nacional, Documento de Trabajo, 25 de mayo de 1977. Municipalidad de Santa Fe. Plan Director de la ciudad de Santa Fe, 1980.

Municipalidad de Santa Fe. Red de enlace ferro-vial del área de influencia de la presa del Paraná Medio cierre Sur Chapetón. Propuesta preliminar, 1981. 